\title{
ESTUDO DA EFICIÊNCIA DO MEIO FILTRANTE DE FIBRAS DE POLÍESTER APÓS FILTRAÇÃO POR PULSO DE AR REVERSO
}

\author{
T.S. SATELES ${ }^{1 *}$; S.S.R. CIRQUEIRA ${ }^{1}$; E.H. TANABE ${ }^{2}$, M.L. AGUIAR ${ }^{1}$ \\ ${ }^{1}$ Universidade Federal de São Carlos, Departamento de Engenharia Química \\ ${ }^{2}$ Universidade Federal de Santa Maria, Departamento de Engenharia Química \\ *e-mail: samirysara@gmail.com
}

\begin{abstract}
RESUMO
O objetivo do trabalho foi estudar a eficiência do meio filtrante, de fibra de poliéster, na remoção de partículas micrométricas de calcário dolomítico, utilizando a técnica de limpeza pulso de ar reverso. Os ensaios de filtração foram realizados mantendo-se a velocidade de filtração constante a $4 \mathrm{~cm} / \mathrm{s}$, com queda de pressão de $100 \mathrm{~Pa}$ e o tempo de pulso de $200 \mathrm{~ms}$, a cada limpeza do meio filtrante. Os parâmetros obtidos experimentalmente foram: queda de pressão residual, massa retida, a eficiência de limpeza e a eficiência de coleta. Deste modo, observou-se que, a eficiência de limpeza do meio filtrante diminuiu com o aumento no número de ciclos. Entretanto, a massa retida, a queda de pressão residual e a eficiência de coleta aumentaram até o quinquagésimo ciclo de filtração. Assim, verificou-se que o meio filtrante de fibra de poliéster regenerado, submetido aos ciclos de filtração, mostrou-se eficiente na coleta de partículas maiores de $3 \mu \mathrm{m}$, mesmo apresentando eficiência de limpeza por pulso de ar reverso menor e queda de pressão residual maior.
\end{abstract}

\section{INTRODUÇÃO}

Os filtros de mangas apresentam uma operação simples de separação gás-sólido, e além desses filtros serem utilizados na coleta e na recuperação de material particulado, eles contribuem no combate à poluição atmosférica (SOUZA et al., 2012).

Os feltros agulhados têm sido utilizados nos filtros de mangas com limpeza por pulso de ar reverso, por serem altamente eficientes na remoção de partículas micrométricas, através da limpeza periódica, possibilitando maior relação ar-tecido, devido à maior quantidade de poros por unidade de área (TANABE, 2008; SALEEM et al., 2011; CERON, 2012).

Os ciclos de filtração por pulso de ar reverso consistem em uma fase de filtração e uma fase de limpeza. A limpeza por essa técnica apresenta eficiência de remoção maior que as demais técnicas de limpeza e a não necessidade de interromper a operação de filtração, permitindo a parcial regeneração do meio filtrante (SIMON et al., 2010). Outro efeito positivo desta técnica está associado à maior eficiência de coleta durante a filtração (SIMON et al., 2007).

Apesar de ser muito utilizado em processos industriais, que envolvem celulose, cal, cimento, sabão em pó, pigmentos, fertilizantes, siderúrgicas, ferro-liga, fundições ferro-cobre e, secador de madeira, ainda apresenta um número escasso de trabalhos científicos relacionados à limpeza por pulso de ar reverso, uma vez que, a maioria dos trabalhos encontrados na literatura está relacionada à filtração de gases por técnica de limpeza por fluxo de ar reverso.

Desta forma, observa-se a necessidade de estudar a regeneração e a eficiência do meio filtrante de fibra de poliéster submetido à técnica de limpeza por pulso de ar reverso, 
verificando-se a influência do número de ciclos de filtração na eficiência de coleta, na massa retida, na queda de pressão residual e na eficiência de limpeza.

\section{MATERIAIS E MÉTODOS}

\subsection{Materiais}

O material particulado utilizado foi o calcário dolomítico, fornecido pela Fosfértil S.A, e o meio filtrante foi o feltro agulhado de fibra de poliéster, com tratamento de gramatura $350 \mathrm{~g} / \mathrm{m}^{2}$, fornecido pela empresa Gino Cacciari.

A caracterização do material particulado foi realizada no Laboratório de Controle Ambiental I, do Departamento de Engenharia Química, da Universidade Federal de São Carlos (UFSCar). Obteve-se a massa específica da partícula por Picnometria a Hélio, o diâmetro médio volumétrico por meio do equipamento Malvern Mastersizer Microplus, a massa e o número de partícula em função do diâmetro aerodinâmico, pelo contador de partículas APS acoplado ao gerador, do Modelo Small Scale Powder Disperser 3433, da Marca TSI, utilizado na alimentação de material particulado.

Para a caracterização do meio filtrante, foram obtidas imagens de três regiões, na superfície e na transversal, por Microscopia Eletrônica de Varredura (MEV), no Laboratório de Caracterização Estrutural, da UFSCar.

As imagens da superfície do meio filtrante foram utilizadas na determinação do diâmetro médio das fibras, por meio do programa de análise de imagens Image Pro Plus 7.0. Entretanto, as imagens do meio filtrante na transversal foram utilizadas na determinação da espessura do meio poroso, por meio do mesmo programa computacional de análise de imagens. Essas análises foram feitas manualmente, calibrando a imagem de acordo com a escala fornecida por cada figura do MEV.

\subsection{Unidade experimental de filtração}

Na Figura 1 está apresentada a unidade experimental utilizada para a realização dos ensaios experimentais de filtração. Esta unidade consiste de um alimentador de partículas, um suporte para o meio filtrante, um sistema de limpeza por pulso de ar reverso, uma placa de orifício e um sistema de aquisição de dados.

Figura 1 - Unidade experimental de filtração

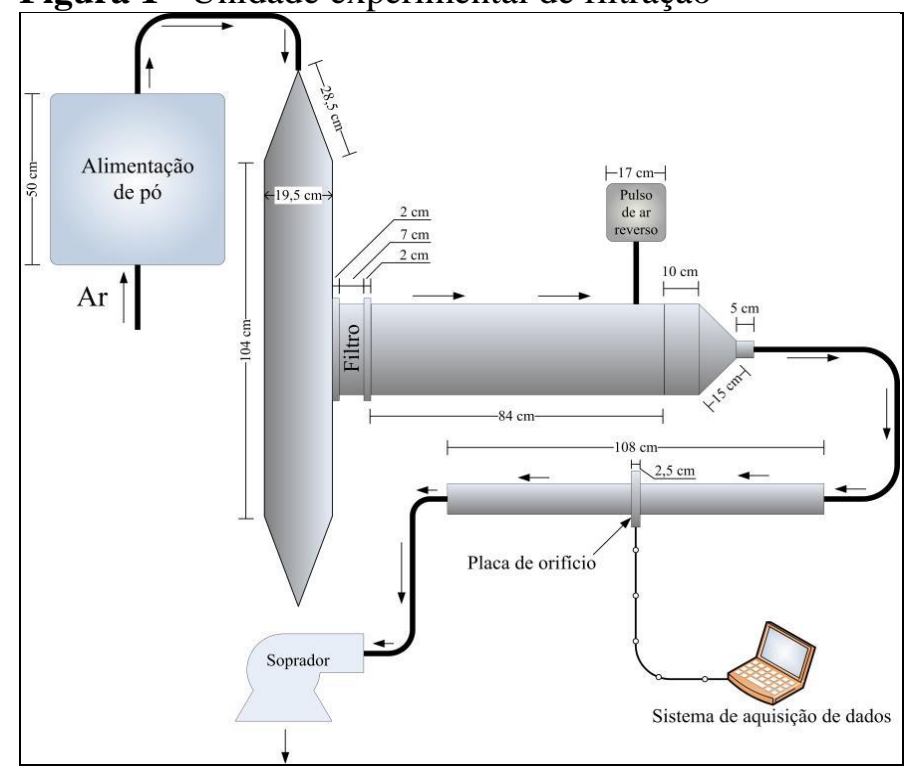

Fonte: CIRQUEIRA et al. (2014).

Esse equipamento apresenta uma área filtrante de $227 \mathrm{~cm}^{2}$. O sistema de aquisição de dados permite o registro da queda de pressão em função do tempo.

Durante a operação de filtração, o valor de queda de pressão pré-estabelecido para cada ciclo de filtração foi de $100 \mathrm{~Pa}$ e a velocidade superficial de filtração foi mantida constante em $4 \mathrm{~cm} / \mathrm{s}$. Foram realizados 50 ciclos de filtração por pulso de ar reverso.

Durante a limpeza do meio filtrante, utilizou-se o tempo de pulso de $200 \mathrm{~ms}$, para o desprendimento da camada de material particulado formada.

\subsection{Eficiência do meio filtrante}

A eficiência do meio filtrante foi obtida através das medidas de concentrações 
de partículas antes e depois do meio filtrante, utilizando um contador de partículas APS (Modelo Aerodynamic Particle Sizer 3320 da Marca TSI). Essas eficiências foram calculadas para cada faixa de diâmetro aerodinâmico de partículas como apresentado na Equação 2:

$E(\%)=\frac{C_{i}-C_{f}}{C_{i}} \cdot 100$

em que $\mathrm{C}_{\mathrm{i}}$ e $\mathrm{C}_{\mathrm{f}}$ referem-se às concentrações de partículas antes e após a passagem pelo meio filtrante, respectivamente.

$\mathrm{Na}$ Figura 2, é apresentado o equipamento utilizado para realização dos ensaios experimentais de eficiência de coleta do meio filtrante (virgem e após os ciclos de filtração), acoplado ao contador de partículas APS. Para determinação da eficiência de coleta, o equipamento foi composto por um gerador de partículas (Modelo Small Scale Powder Disperser 3433 da Marca TSI), meio filtrante, rotâmetro, APS contador de partículas, computador e bomba de sucção.

Essa determinação de eficiência de coleta foi realizada no mesmo meio filtrante utilizado nos ensaios de filtração e a velocidade foi mantida constante e igual a dos ensaios de filtração $(4 \mathrm{~cm} / \mathrm{s})$.

Figura 2 - Unidade experimental de eficiência de coleta.

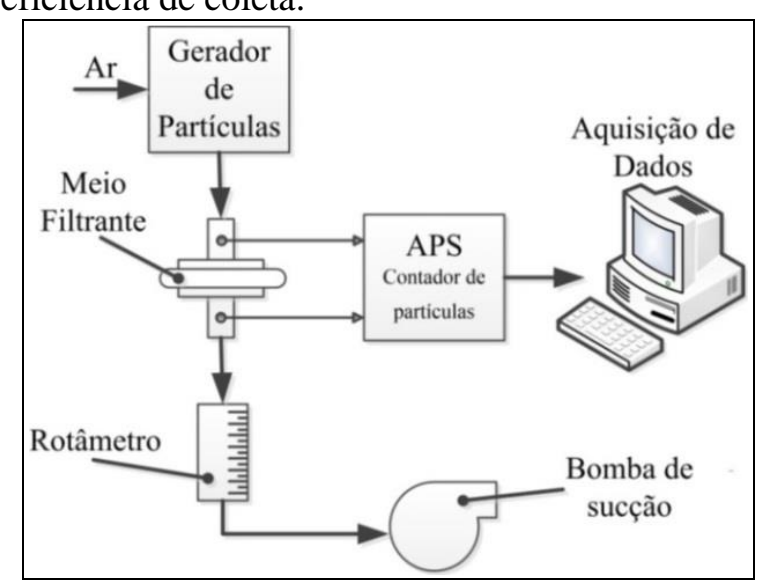

Fonte: Acervo pessoal (2015).

\subsection{Cálculo da eficiência de remoção da torta do tecido}

A eficiência de limpeza por pulso reverso $\left(\eta_{\mathrm{L}}\right)$ é determinada por meio da queda de pressão no meio filtrante $\left(\Delta \mathrm{P}_{\mathrm{m}}\right)$, da queda de pressão residual $\left(\Delta \mathrm{P}_{\mathrm{R}}\right)$ e da queda de pressão inicial $\left(\Delta \mathrm{P}_{\mathrm{i}}\right)$, representada pela equação (LEE et al., 2015 apud ZHONGLI et al., 2004):

$\eta_{L}=\frac{\left(\Delta P_{m}-\Delta P_{R}\right)}{\left(\Delta P_{m}-\Delta P_{i}\right)} \cdot 100$

\section{RESULTADOS E DISCUSSÕES}

\subsection{Caracterização dos materiais}

\subsubsection{Material pulverulento}

O material particulado utilizado foi o calcário dolomítico, cuja massa específica da partícula corresponde a $2,75 \mathrm{~g} / \mathrm{cm}^{3}$, obtida pela média de três análises (Picnometria a Hélio e AccuPyc 1330 Micrometrics). E o diâmetro médio volumétrico desta partícula apresentou 9,74 $\mu \mathrm{m}$ (Malvern Mastersizer Microplus), conforme a Figura 3.

Figura 3 - Distribuição granulométrica do calcário dolomítico (massa acumulada em função do diâmetro volumétrico de partícula).

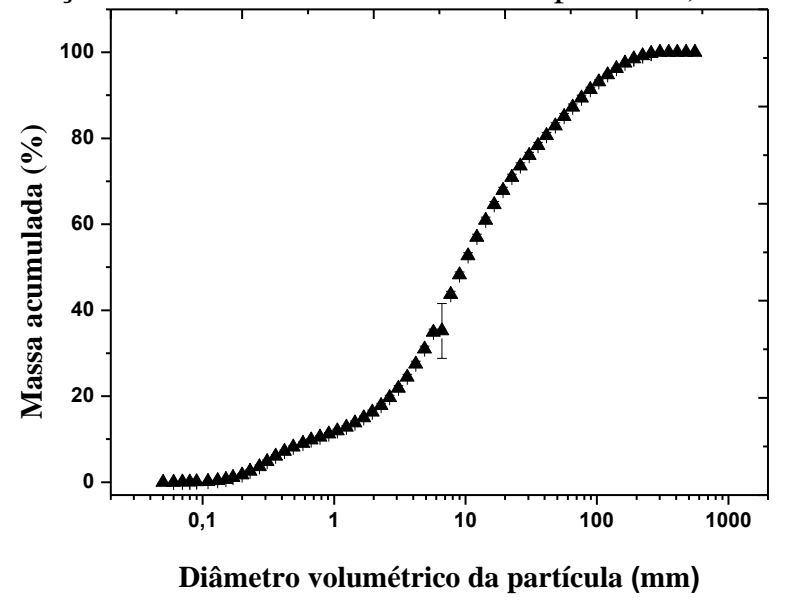

Fonte: Acervo pessoal (2015).

Além do diâmetro médio volumétrico, verificou-se a necessidade de observar a faixa 
de diâmetro médio aerodinâmico da partícula que era detectada em massa e número pelo contador de partículas APS, devido à sua utilização na determinação da eficiência do meio filtrante. Para isso, foi utilizado o equipamento apresentado na Figura 2, contendo apenas o gerador de partículas, o contador de partículas APS e o computador para aquisição de dados. Na Figura 4 está apresentada a massa e o número de partículas em função do diâmetro aerodinâmico de partículas.

Figura 4 - Massa e número de partículas em função do diâmetro aerodinâmico, realizada pelo equipamento de alimentação de partículas acoplado ao APS.

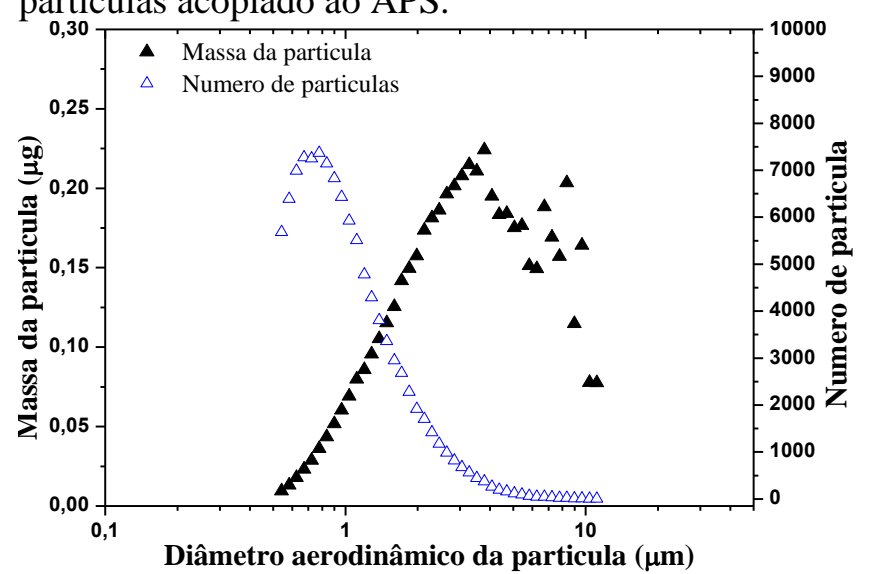

Fonte: Acervo pessoal (2015).

Analisando a Figura 4, verificou-se que, a faixa compreendida pelo diâmetro aerodinâmico de partículas foi de 0,542 a $11,14 \mu \mathrm{m}$, para a massa e o número de partículas. Também nesta figura, observou-se o decréscimo no número de partículas, devido ao aumento da massa da partícula e do diâmetro aerodinâmico.

\subsubsection{Meio filtrante}

$\mathrm{Na}$ Figura 5, está apresentada uma das três imagens obtidas em MEV (a) da superfície e (b) na transversal do meio filtrante. Por meio dessas figuras e do programa de análise de imagens Image Pro Plus 7.0, obteve-se o diâmetro médio das fibras $(19,81 \mu \mathrm{m})$ e a espessura média do meio poroso $(1,54 \mathrm{~mm})$.

Figura 5 - Microscopia eletrônica de varredura do feltro agulhado de fibra de poliéster (a) na superfície e (b) na transversal.

(a)

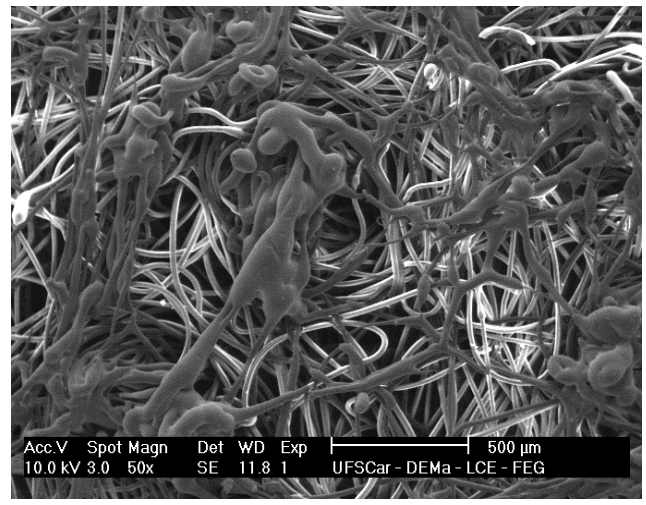

(b)

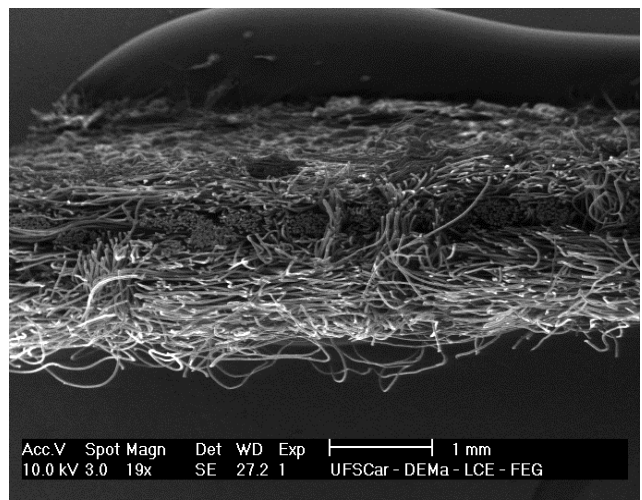

Fonte: Acervo pessoal (2015).

\subsection{Ensaios de filtração}

A deposição das partículas foi verificada até uma queda de pressão máxima de $100 \mathrm{~Pa}$, utilizando a velocidade superficial do gás de $4 \mathrm{~cm} / \mathrm{s}$. Esses ensaios de filtração foram realizados em triplicatas, porém todos os ensaios apresentaram semelhantes. A Figura 6 apresenta os 50 ciclos de filtração, em um dos três ensaios realizados, representados pela queda de pressão em função do tempo de filtração.

Observa-se que, no instante inicial da filtração, a curva apresentou inclinação menor, quando comparada aos demais ciclos de filtração, devido à ocorrência da filtração interna. No entanto, após o primeiro ciclo de 
filtração, as curvas tornaram-se mais acentuadas, referente à remoção incompleta de material particulado, característico de uma filtração superficial. Desta forma, verificou-se a ocorrência da transição entre a filtração interna e a filtração superficial, chamado de ponto de colmatação ou de entupimento do meio filtrante.

Figura 6 - Ciclos de filtração: queda de pressão em função do tempo de filtração.

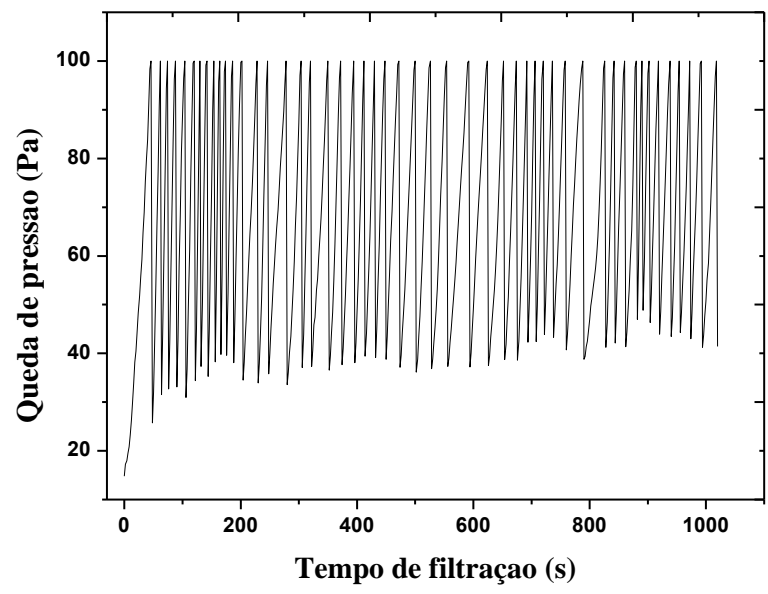

Fonte: Acervo pessoal (2015).

\subsection{Características da remoção da torta}

$\mathrm{Na}$ Figura 7, está apresentada a influência do número de ciclos de filtração em função do tempo médio de filtração, para os três ensaios realizados.

Figura 7 - Número de ciclos de filtração em função do tempo médio de filtração.

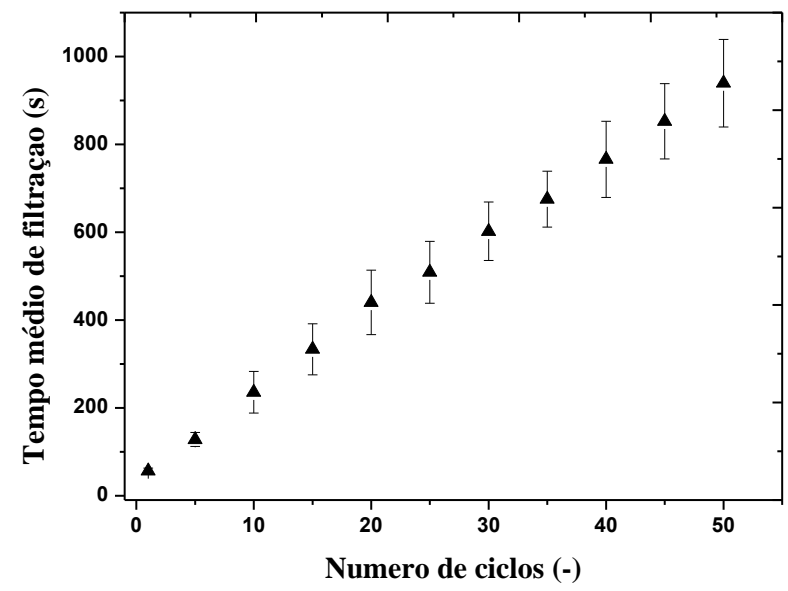

Fonte: Acervo pessoal (2015).
Ao analisar a Figura 7, observou-se que o meio filtrante de fibra de poliéster de $350 \mathrm{~g} / \mathrm{m}^{2}$ mostrou distintos valores de tempos de filtração, a cada cinco ciclos de filtração, apresentando assim, uma tendência de aumento do tempo de filtração em função do número de ciclos.

A queda de pressão total aumenta, devido à deposição de partículas sobre a superfície do filtro de fibras de poliéster, com o tempo de operação da filtração. Para garantir um funcionamento regular desse meio filtrante, a camada de pó de calcário foi removida por pulso de ar reverso, em tempo de pulso determinado $(200 \mathrm{~ms})$, promovendo assim, a sua regeneração entre os intervalos de limpeza. A queda de pressão no meio filtrante após a remoção da camada de pó é chamada de queda de pressão residual e está representada na Figura 8, em função do número de ciclos de filtração.

Figura 8 - Queda de pressão residual em função do número de ciclos de filtração, média dos três ensaios de filtração.

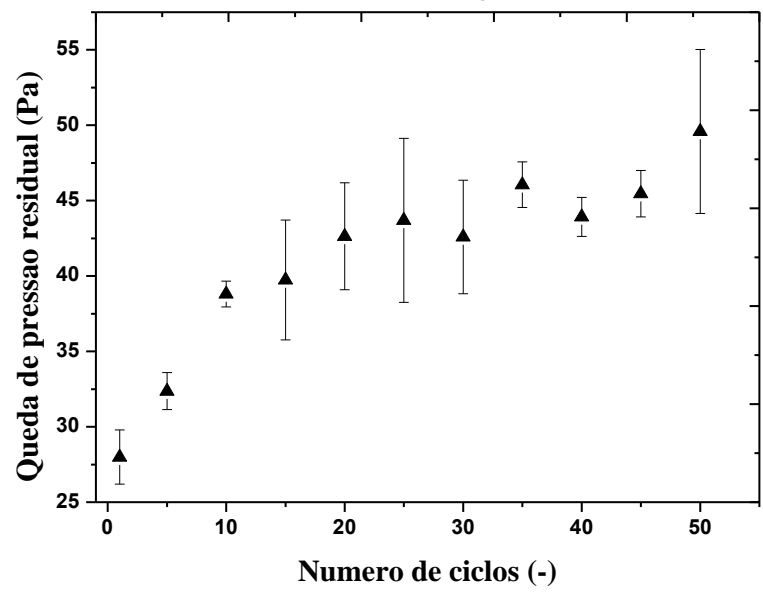

Fonte: Acervo pessoal (2015).

O maior tempo médio de filtração e a maior queda de pressão residual média após a limpeza do meio filtrante foram observados após o quinquagésimo ciclo de filtração. Desta forma, pode-se verificar que, à medida que se aumentou o número de ciclos de filtração, mais partículas foram depositadas 
no meio filtrante. Isso pode ser atribuído ao aumento da massa retida, já que após o primeiro, o vigésimo quinto $\mathrm{e} \quad \mathrm{o}$ cinquentésimo ciclo, a massa retida após a limpeza foi de $6,7 \times 10^{-3} \mathrm{~g} / \mathrm{cm}^{2}( \pm 0,03 \%)$, de $6,7 \times 10^{-3} \mathrm{~g} / \mathrm{cm}^{2}( \pm 0,07 \%)$ e de $1,2 \times 10^{-2} \mathrm{~g} / \mathrm{cm}^{2}$ $( \pm 0,01 \%)$, respectivamente.

\subsection{Eficiência de remoção da torta do tecido}

Na Figura 9, estão apresentadas as eficiências de limpeza por pulso de ar reverso, médias dos três ensaios realizados, obtidas por meio da Equação 2.

Figura 9 - Eficiência de limpeza por pulso de ar reverso em função do número de intervalos de limpeza do meio filtrante.

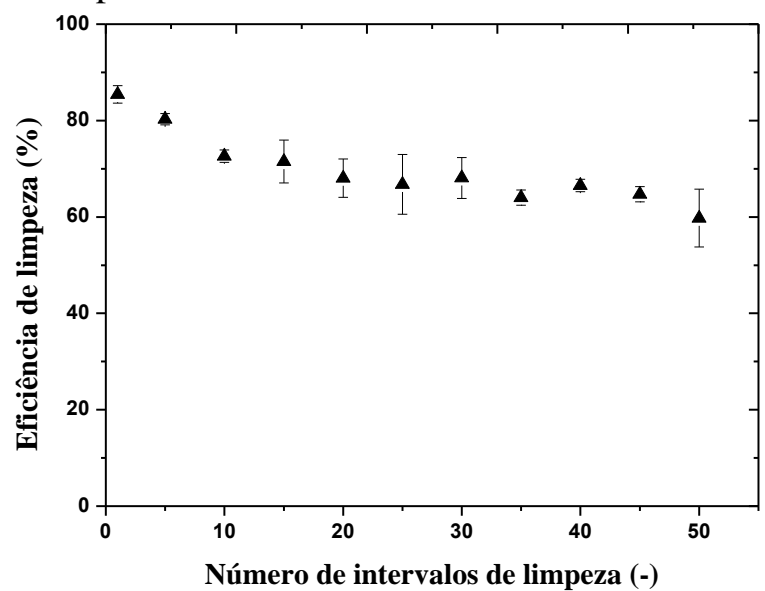

Fonte: Acervo pessoal (2015).

É possível observar que a eficiência de limpeza foi alta para o primeiro intervalo de limpeza $(85,44 \%)$. Entretanto, mostrou-se uma tendência de decréscimo dessa eficiência com o aumento dos intervalos de limpeza por pulso de ar reverso, até 59,76\% de eficiência de limpeza, como apresentado no quinquagésimo intervalo de limpeza. Isso é explicado devido à influência da massa retida e da queda de pressão residual após cada limpeza do meio filtrante, ocasionando um aumento das partículas retidas no interior do meio filtrante e promovendo assim, uma maior resistência à limpeza e uma redução na sua eficiência de remoção da torta.

\subsection{Eficiência de coleta do meio filtrante}

$\mathrm{Na}$ Figura 10, são mostradas as eficiências de coletas do meio filtrante virgem comparadas a eficiência (a) depois de submetidos a 1 ciclo, (b) a 25 ciclos e, (c) a 50 ciclos de filtração, obtidas por meio da Equação 1, referente à concentração de coleta de partículas por diâmetro das partículas.

Figura 10 - Eficiência de coleta do meio filtrante virgem comparadas a eficiência do tecido, após (a) 1 ciclo, (b) 25 ciclos e (c) 50 ciclos de filtração.
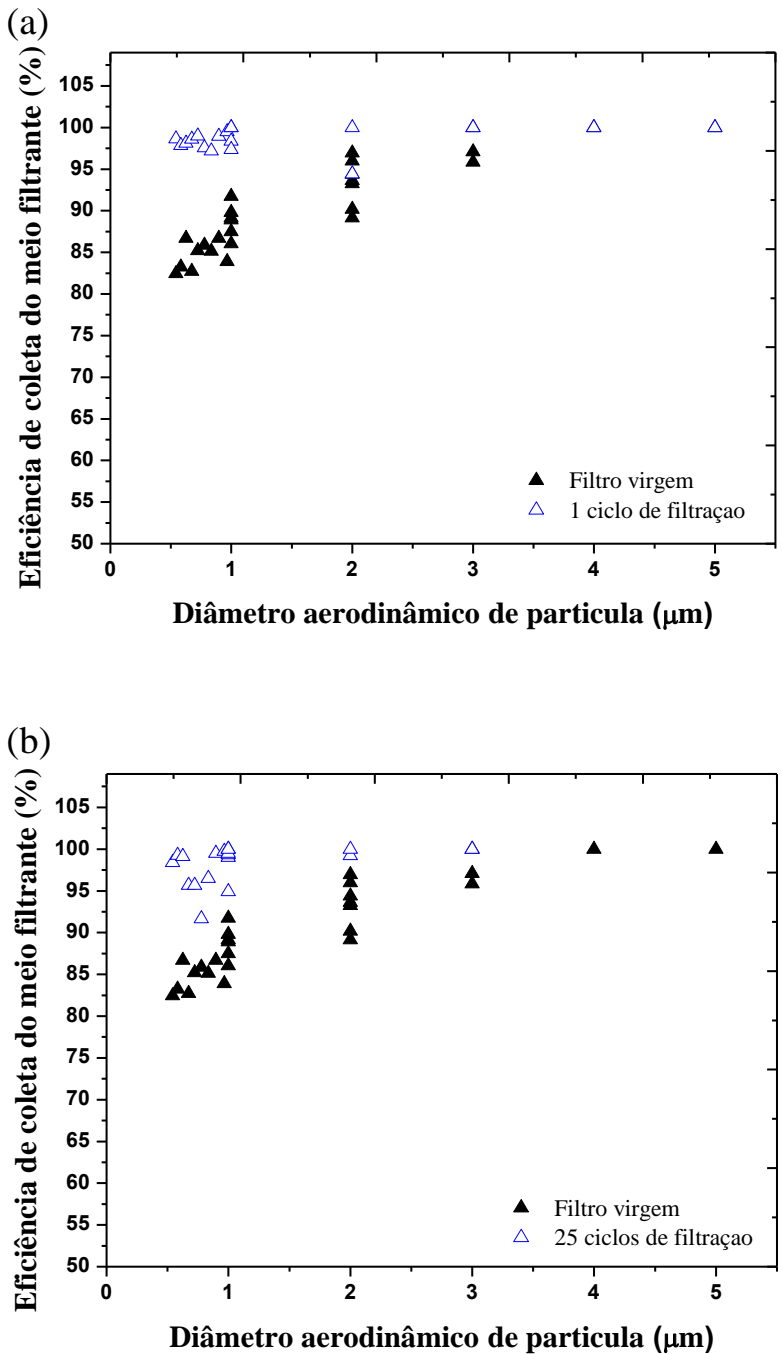


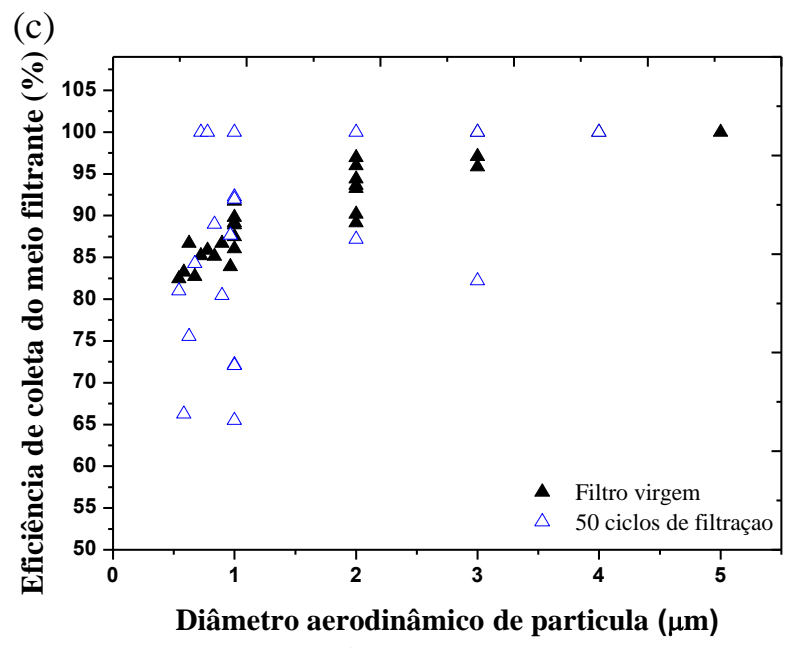

Fonte: Acervo pessoal (2015).

A análise da Figura 10 revela que a eficiência de coleta do meio filtrante aumentou com os diâmetros de partículas avaliados, sendo que, para a maioria dos diâmetros verificados, a eficiência de coleta foi de aproximadamente $100 \%$. O meio filtrante apresentou-se mais eficiente na coleta de partículas após o primeiro ciclo de limpeza, quando comparado ao mesmo meio filtrante virgem. Entretanto, após 25 e 50 ciclos, esse meio filtrante mostrou-se menos eficiente na coleta de partículas menores que $1 \mu \mathrm{m}$, em relação ao filtro submetido a apenas 1 ciclo de filtração.

\section{CONCLUSÕES}

De acordo com os resultados obtidos, foi possível concluir o seguinte:

$>$ Nos ensaios de filtração verificou-se que a deposição de partículas apresentou duas etapas, filtração interna e filtração superficial;

Através dos valores de tempo de filtração e de queda de pressão residual, observou-se uma tendência no aumento com o número de ciclos de filtração. Entretanto, esses maiores valores foram observados após $\mathrm{o}$ quinquagésimo ciclo;
Assim como o tempo de filtração e a queda de pressão residual, a massa retida também aumentou com o número de ciclos, de $6,7 \times 10^{-3} \mathrm{~g} / \mathrm{cm}^{2}$ para o primeiro ciclo até $1,2 \times 10^{-2}$ $\mathrm{g} / \mathrm{cm}^{2}$ referente ao quinquagésimo ciclo de filtração;

$>$ A eficiência de remoção da torta apresentou um decréscimo, de 85,44\% no primeiro ciclo e $59,76 \%$ no último ciclo avaliado. Entretanto, a eficiência de coleta do meio filtrante foi maior após os ciclos de filtração para partículas de diâmetros maiores que 3 $\mu \mathrm{m}$. Por isso, pode-se dizer que o meio filtrante, submetido aos ciclos de filtração, torna-se mais eficiente na coleta de partículas maiores de $3 \mu \mathrm{m}$, porém sua eficiência de remoção da torta por pulso de ar reverso apresenta-se menor;

$>$ Contudo, após os cinquenta ciclos de filtração, o tecido ainda se mostrou adequado para ser utilizado em outros ciclos de filtração, devido à queda de pressão residual ter apresentado metade do valor da queda de pressão máxima e, a eficiência de remoção da torta do tecido apresentou maior que $50 \%$. Assim, observou-se que, o meio filtrante de fibra de poliéster não foi saturado e não sofreu desgaste do tecido ao ponto de troca do meio filtrante nas condições operacionais avaliadas.

\section{NOMENCLATURA}

$\eta_{\mathrm{L}} \quad$ Eficiência de limpeza

$\Delta \mathrm{P}_{\mathrm{m}} \quad$ Queda de pressão no meio filtrante

$\Delta \mathrm{P}_{\mathrm{R}} \quad$ Queda de pressão residual

$\Delta \mathrm{P}_{\mathrm{i}} \quad$ Queda de pressão inicial

E Eficiência de coleta

$\mathrm{Ci}$ Concentração inicial

$\mathrm{Cf}$ Concentração final 


\section{REFERÊNCIAS}

CERON, L. P. Desenvolvimento de filtro cartucho de polimida para altas temperaturas com resina epóxi dgeba e novo agente de cura. Tese de Doutorado. Pontifícia Universidade Católica do Rio Grande do Sul, Porto Alegre, 2012.

CIRQUEIRA， S.S.R.; TANABE， E.H.; AGUIAR, M.L. Avaliação da regeneração dos meios filtrantes após duzentos ciclos de filtração por pulso de ar reverso. In: XX Congresso Brasileiro de Engenharia Química, 2014, Florianópolis. Anais do XX Congresso Brasileiro de Engenharia Química. São Paulo: Editora Edgard Blücher. p. 9479-9486.

LEE, K., SOHN, J-R., PARK, Y.O. Filtration performance characteristics of ceramic candle filter based on inlet structure of hightemperature and high-pressure dust collectors. Journal of industrial and engineering chemistry 21, p. 101-110, 2015.

SALEEM, M.; KRAMMER, G.M.; TAHIR, $S$. The effect of operating conditions on resistance parameters of filter media and limestone dust cake for uniformly loaded needle felts in a pilot scale test facility at ambient conditions. Powder Technology, v. 228, p.100-107, 2012.

SIMON, X.; BÉMER, D.; CHAZELET, S.; THOMAS, D.; RÉGNIER, R. Consequences of high transitory airflows generated by segmented pulse-jet cleaning of dust collector filter bags. Powder Technology v.201, p.3748, 2010.

SIMON, X; CHAZELET, S; THOMAS, D; BÉMER, D; RÉGNIER, R. Experimen,tal study of pulse-jet cleaning of bag filters supported by rigid rings. Powder Technology v.172, p.67-81, 2007.

SOUZA, F. M. N.; SILVA, C. E.; AGUIAR, L. A.; ALMEIDA, J. R.. Análise de riscos como instrumento para sistemas de gestão ambiental. Revista Ibero Americana de Ciências Ambientais, Aquidabã, v.3, n.1,p.17-41, 2012.

TANABE, E. H. Estudo do comportamento da deposição das partículas de diferentes meios filtrantes. Dissertação de Mestrado. Universidade Federal de São Carlos. São Carlos, 2008. 